\title{
The element in the room
}

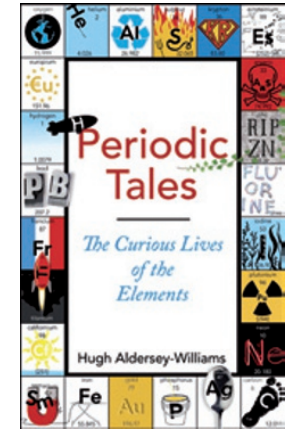

Periodic Tales: The Curious Lives of the Elements

By Hugh AlderseyWilliams

VIKING: 2011

288 PP. $€ 18.99$

eing a chemist sometimes has its down side. When I tell people what I do for a living, they often reply that they hated chemistry, or failed it, or found it impossibly difficult. Sometimes they add that it was all very dry and boring. Apart from it being rather rude (if you meet an accountant do you tell them how dull you think their profession is?), it speaks volumes about how the presentation and teaching of chemistry fails to capture the imaginations of both children and adults. Tragically, the subject is often reduced to a succession of abstract equations, trends in properties, semisubstantiated fears about 'chemicals', and an expectation of, if not an explosion, then at least a small fire.

What is missing is the sense of how profoundly chemistry in general, and the elements in particular, are embedded in our culture and our language. We feel we have arrived if we are given use of a gold or even a platinum credit card. Mercury, for all our fears of its properties, gives an exotic feel to 'skins' for video games, whereas the apparent oxymoron liquid metal was used to underscore the alien-ness of the Terminator. Titanium, often just the name, lends an impression of strength and exoticism to consumer products, whereas the element itself confers a strange luminous glow on Frank Gehry’s Guggenheim Museum in Bilbao.

It is precisely these kinds of connections that Hugh Aldersey-Williams captures so effectively in Periodic Tales, a book that flits effortlessly from one element to another, weaving a complex skein between use, abuse, history, meaning and symbolism of the ninety-something elements in common use. Gold is introduced not through jewellery or archaeology, but through a life-size statue of Kate Moss. Aldersey-Williams then moves on to the allegorical meaning of gold, with an exploration of how gold has become the metaphor and expression of all that is durable and valuable, but the accompanying sense that gold, and the greed it engenders, corrupts man. Pliny the Elder wished it could be "banished from life" whereas Thomas More had the Utopian vision of golden chamber-pots.

The pace is sometimes almost dizzying, the breadth of material (history of science, poetry, sculpture, film, comics and more) astonishing, and the order in which the elements come is unconventional and refreshing. Fire evokes, in order, sulfur, phosphorus, the halogens, oxygen, radium and the alkali metals. For several of these elements, there is something of a quest: a quixotic attempt to smelt

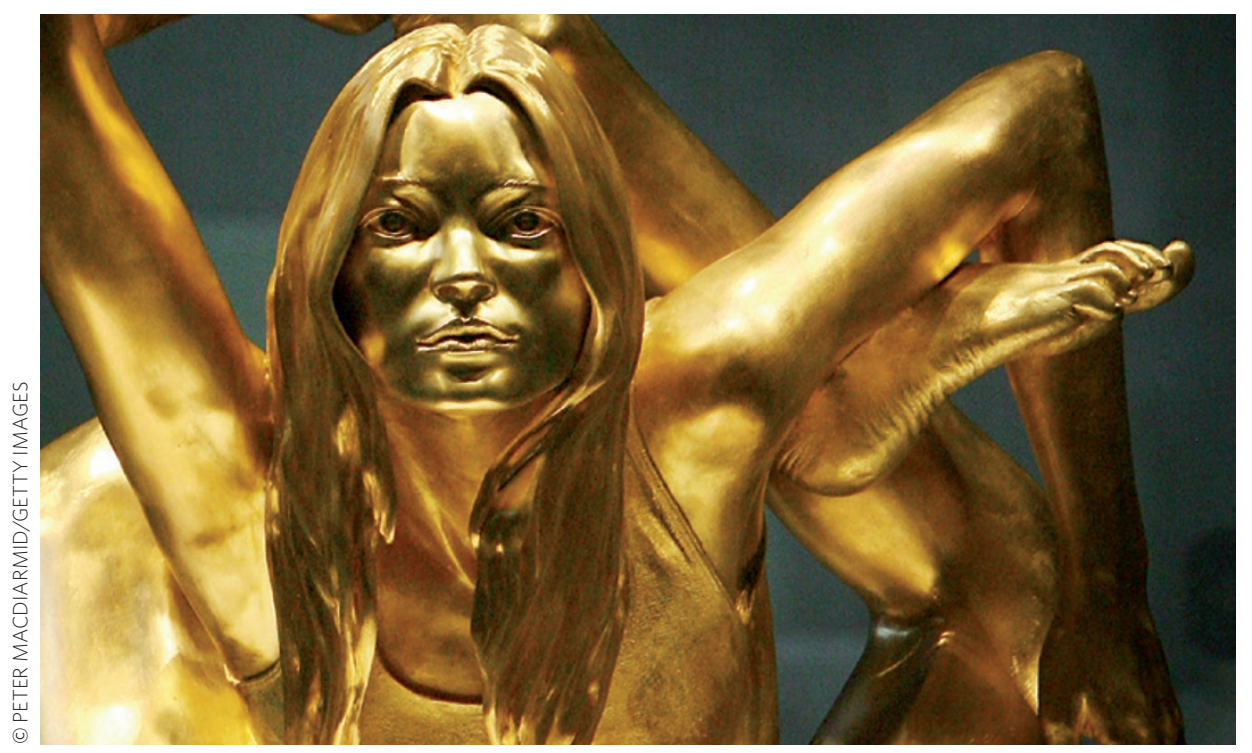

phosphorus; a visit to a charcoal furnace; a depressing trip to the original source of the rare earths. There is something delightfully whimsical in this game of word- and thoughtassociation, and plenty of mad parallels to make one sit up and take notice.

This approach will perhaps be irritating to anyone wanting to see the bigger picture. The ideas are fleeting and dance about — passing quickly from one thing to another. But how else could one do it with so many elements to cover? If I have one reservation, it is that the book is light on geopolitics and finance. Can one really speak of niobium and tantalum simply in terms of how they can be used for jewellery, without mentioning how our insatiable demand for consumer electronics fuels the wars devastating eastern Congo? There is also no mention of the modern South Sea bubbles driven by elemental speculation, such as the Hunt brothers' attempt to corner the silver market in the 1970s or the Sumitomo copper scandal.

As a lanthanide chemist, I am a little saddened by Aldersey-Williams' palpable disappointment at the end of his quest to find the rare earths. Their bizarre history is covered in detail and the delicious currency joke is included (I won't give it away). But it is odd that here copper is the World Wide Web whereas erbium, whose unique, blazing emission at $1.55 \mu \mathrm{m}$ lights up the fibre optics of our modern communications, isn't mentioned. It is remarkable how recent Chinese quotas imposed on rare-earth exports - too recent for inclusion in the book have heightened atavistic fears of the loss of Western supremacy. But perhaps it is too soon for erbium to have a real cultural resonance, having yet to appear in verse or even popular music (with all due respect to Tom Lehrer).

These issues aside, what one is left with is a real sense of the glory of the periodic table and its denizens. No chemist or teacher of chemistry should be without this book. It provides a myriad of ways of making the ninety-two symbols printed on the walls of our labs and classrooms leap back into the real lives of real people everywhere. For any chemist interested in an unconventional view of the elements, Periodic Tales will feel like a new beginning. And those who hated chemistry in school will, I hope, begin to realize what they missed.

\section{REVIEWED BY ANDREA SELLA}

Andrea Sella teaches chemistry at University College London and is an EPSRC Senior Media Fellow. 